\title{
Brachial lifting using the balanced triple-vector (BTV) technique with dual opposing flaps
}

\author{
Fabio Fantozzi
}

Received: 19 May 2013 / Accepted: 6 October 2013 /Published online: 21 December 2013

(C) The Author(s) 2013. This article is published with open access at Springerlink.com

\begin{abstract}
Background Brachioplasty often involves removing excess skin. Many traditional approaches to this form of surgery are prone to complications and imperfect healing of the incisions. Traditional techniques usually take little or no account of the force vectors that are subsequently applied to the incision after the operation. This contributes towards scarring and other complications.

Method The proposed technique involves the explicit application of three balanced force vectors that greatly reduce scar-related complications. Although the scar is longer, it is on the medial side of the arm and usually fades away completely over time, with greatly improved aesthetic results. A closely related aspect of this technique is the application of anthropometric techniques in order to plan the operation for best results.

Results The proposed technique has been applied in practice to 23 patients. There were no long-term complications. Temporary paresthesia was observed in 5 patients and temporary swelling of hands in 2 patients. One case of seroma was also detected. Two patient required surgical scar revision. One patient was unsastified with the final scar quality.

Conclusions Due to the superficial resection in this technique, no damage to the subcutaneous tissue and lymphatic network occurs, resulting in a more predictable outcome with greatly reduced risk of complications. This technique is particularly good at reducing the scar retraction issues most common when using other single-vector approaches.

Level of Evidence: Level IV, therapeutic study.
\end{abstract}

F. Fantozzi $(\bowtie)$

ACEIP (European Surgical Association of Prof. Ivo Pitanguy

Alumni), Rome, Italy

e-mail: fa.fantozzi@tiscali.it
Keywords Brachial lifting · Brachioplasty $\cdot$ Balanced triple vectors $\cdot$ BTV $\cdot$ Anthropometry $\cdot$ Conical frustum . Complications $\cdot$ Scar retraction

\section{Introduction}

Brachioplasty often involves removing excess skin. Many traditional approaches to this form of surgery are prone to complications and imperfect healing of the incisions.

A secondary issue is the lack of a viable objective method for determining what skin needs to be removed and from where. I have applied an anthropometric approach building on the work of the nineteenth century sculptor Carlo Rochet [1], which resulted in an earlier paper on the application of anthropometry to torsoplastic surgery [2].

The arm is a very flexible limb located close to the head and with the ability to be rotated in many axes. This complicates the measurement of the arm, and as its position also changes its measurements - raised overhead, raised in front of the body and lowered - it is recommended to ensure that a consistent pose is used when measuring patients. The proportions also vary according to gender and race (Fig. 1).

As I have already discussed an objective anthropometric approach to aesthetic and plastic surgery in detail in an earlier article [2], I will limit myself to discussing only those elements that directly relate to the subject of this paper.

The primary objective of this paper is to explain my balanced triple-vector approach to brachial lifting and explain how the more even spread of forces along the arm greatly reduces complications and long-term scarring problems. 


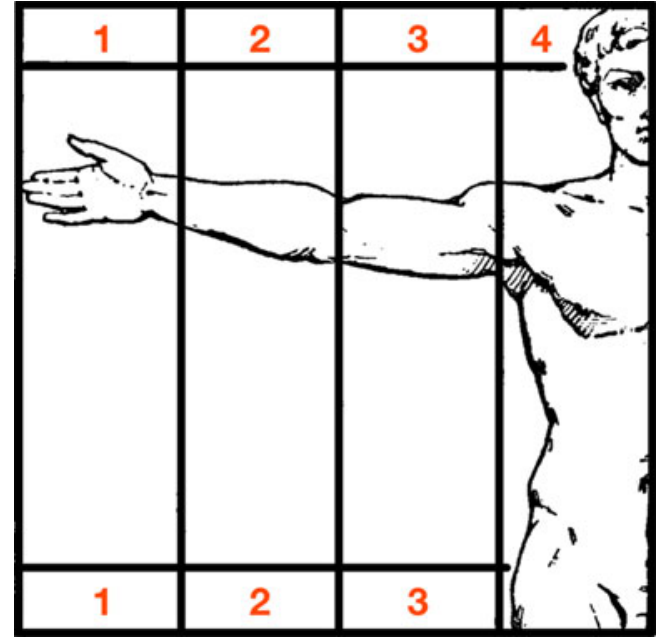

Fig. 1 Measurement of the arm (This figure is based on an image provided by nineteenth century sculptor Carlo Rochet in his 1887 booK.)

\section{Material and methods}

Between January 2009 and January 2013, a retrospective study of all patients undergoing brachioplasty with the BTV technique was undertaken. Their clinical records were reviewed with respect to age, sex, operative time, additional procedures and also complications.

\section{Identifying the excess skin}

The quantity of excess skin removed from the arm must be geometrically proportional to the forearm to avoid changing the anthropometry of the upper limb. Anthropometric studies

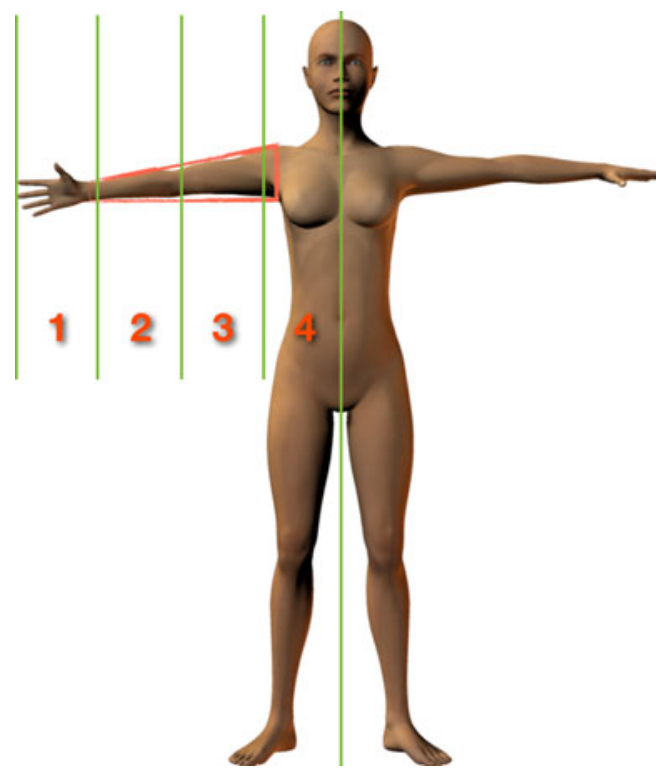

Fig. 2 Projection of a truncated cone

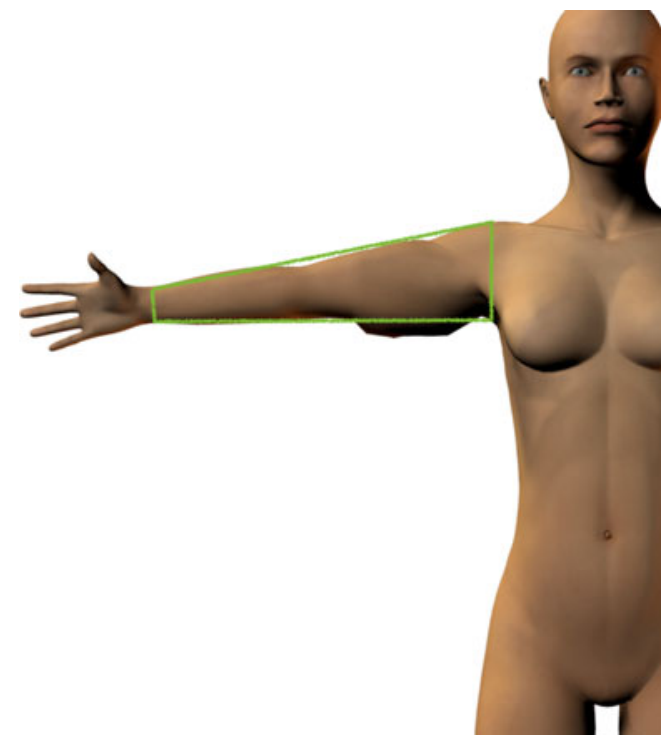

Fig. 3 Branchial lifting for parts outside the truncated cone

show that the best way to determine the amount of excess skin to remove is to project a truncated cone (known as a conical frustum) from the armpit and deltoid to the wrist. An example is shown in Fig. 2 (in red). This defines the 'ideal' proportions of each part of the limb. Any skin that lies outside this truncated cone should be considered for removal.

In Fig. 3, part of the upper arm is outside the truncated cone and is therefore not in proportion with the shoulder, forearm and torso.

Brachial lifting can be used to reduce the size of the upper arm and produce better proportions. The result of the surgery should restore the correct proportions of the upper arm. The truncated cone shows where the work needs to be done: After surgery, the upper arm is now entirely within the truncated

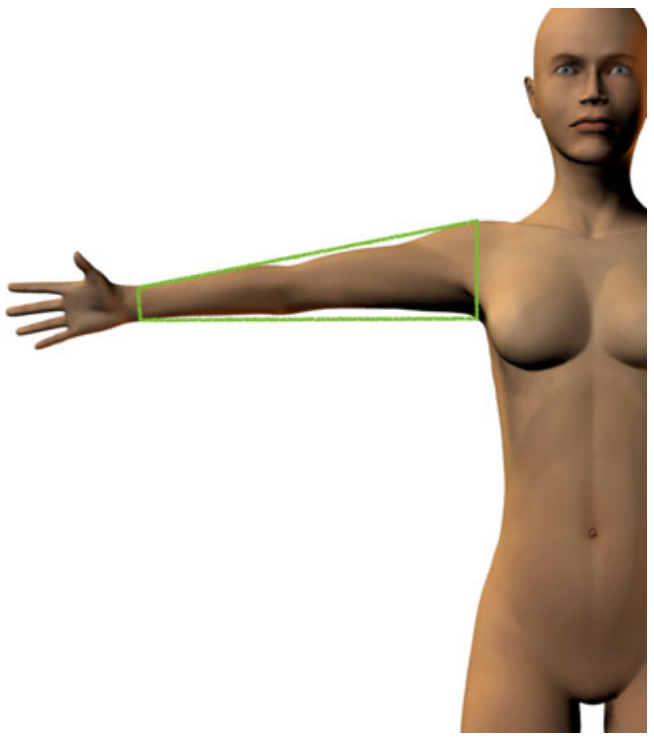

Fig. 4 Post-surgery image of the arm which was outside the truncated zone 


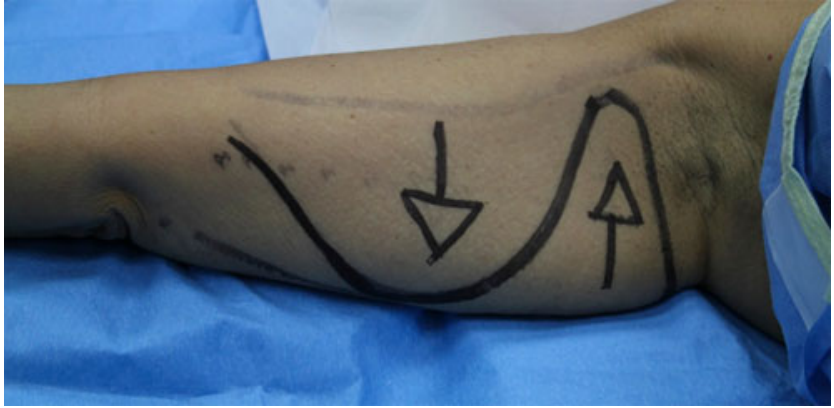

Fig. 5 Shorter curve closest to the shoulder

cone (Fig. 4). It is in proportion with the rest of the torso, the shoulder and the forearm:

By ensuring that the arm is contained within the conical frustum, we achieve the desired aesthetic result.

\section{Surgical procedure}

The incision is formed of two curves: one long (for flap 'A') and one short (flap ' $\mathrm{B}$ '). The shorter curve is closest to the shoulder (Fig. 5.). The use of a curved incision reduces scar retraction.

\section{Anaesthesia}

The following was used for systemic sedation: midazolan $(0.1-0.3 \mathrm{mg} / \mathrm{kg})$, propophol $\left(0.025 \mathrm{mg} \mathrm{kg}^{-1} \mathrm{~min}^{-1}\right)$ and fentanyl (50 $\mu \mathrm{g}$, slowly) with local anaesthesia-Ringer's lactate solution $(1,000 \mathrm{ml})$, carbocaine $2 \%(25 \mathrm{ml})$, sodium bicarbonate $(10 \mathrm{ml})$ and adrenaline $(1 \mathrm{ml})$.

In the following example, the patient has no excess of fat, but does have an excess of skin.

- For patients with excess fat, a liposuction phase is necessary prior to making incision, shown in the second step.

- For patients without excess fat, we can move directly to the incision and traction of the two flaps.

We begin by marking out the intended line of the incision along the medial part of the arm.

Two curves are drawn: the first (distal) curve defines the larger of the two flaps (referred to in the rest of this text as 'flap

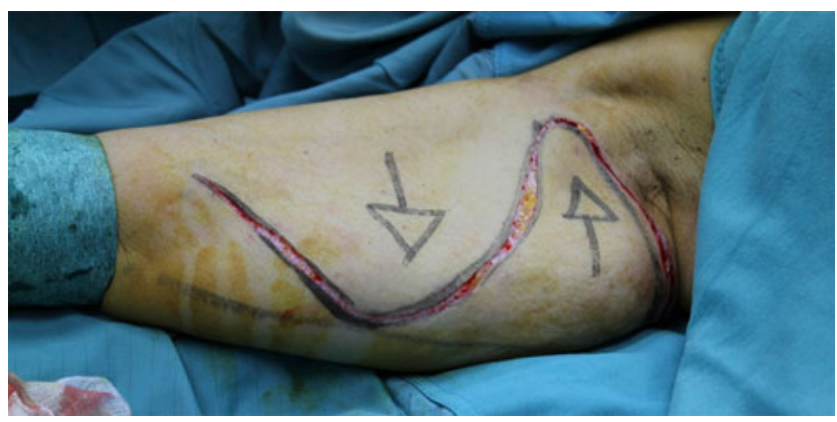

Fig. 6 Sub-dermic incision resulting in flaps A and B

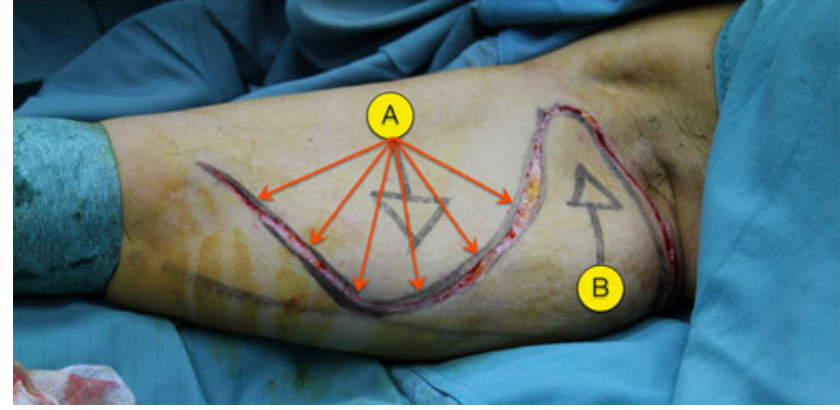

Fig. 7 Traction direction for Flap A

$\left.\mathrm{A}^{\prime}\right)$ and takes up about $75 \%$ of the incision; the second (proximal) curve defines the smaller of the two flaps ('flap B') and occupies $25 \%$. The incision follows these curves and thus creates two opposing flaps. Figure 6 shows the sub-dermic incision that results in the two sub-dermic flaps (A and B); it should be noted that if the patient also requires liposuction, that procedure should be performed prior to this step.

Figures 7,8 and 9 show the intended traction steps we will follow shortly. The first step, then, is to lift, separate and apply downwards traction to flap A. The flap is lifted carefully (Fig. 10) in order to detach the skin from the rest of the arm beneath and prepare it for the downward traction. This subdermic separation of Flap A minimises adipose tissue trauma.

The traction movement (Fig. 11) lets us determine exactly how much skin needs to be excised and mark this on the skin. The excess skin can then be removed.

Now, we temporarily suture flap A (Fig. 12), using Monocryl 3.0 and 4.0 to hold it in place while we work on flap B.

For flap B, we repeat the process applied to flap A, by applying the desired upward traction. Again, the flap must first be lifted carefully to separate it and allow safe traction (Fig. 13).

It is critical that traction is applied first to flap A, then to flap B, in that order. They are not moved simultaneously.

Flap B is the key to success in this procedure. Not only is the skin excised from the flap's upper curve (Fig. 14), but some is also removed from the sides. The resulting traction applies tension to the skin once the incision is finally closed,

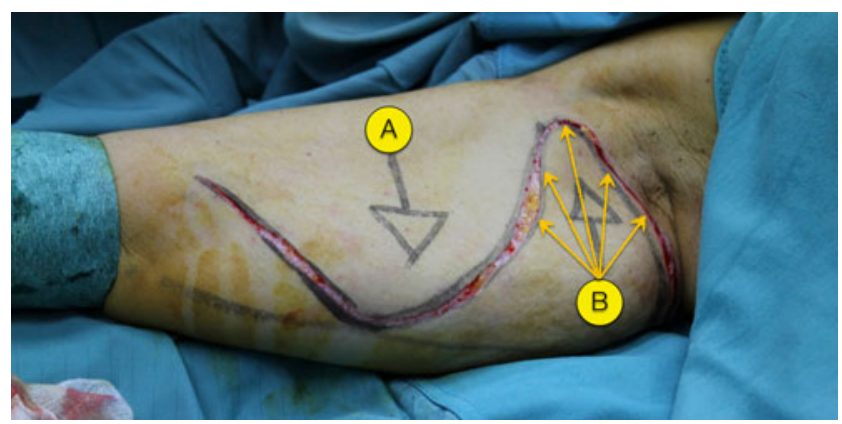

Fig. 8 Traction direction for Flap B 


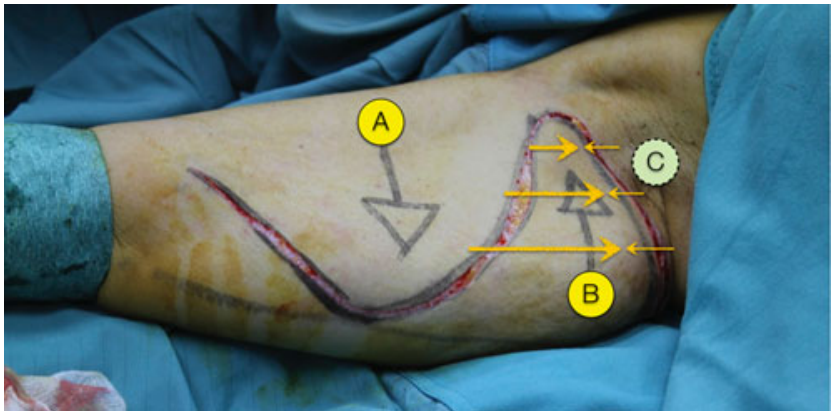

Fig. 9 Traction vectors, showing force vector $\mathrm{C}$

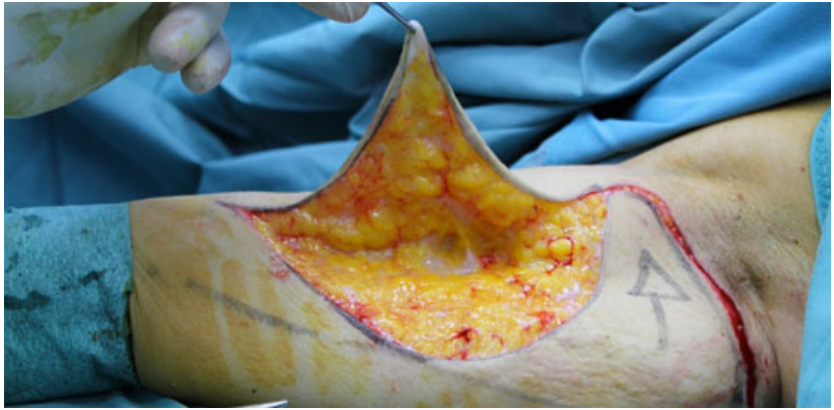

Fig. 10 Separation of flap

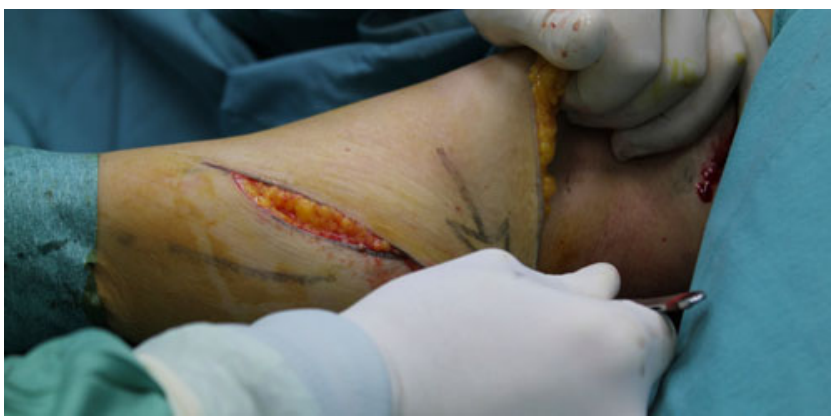

Fig. 11 Traction direction for Flap A

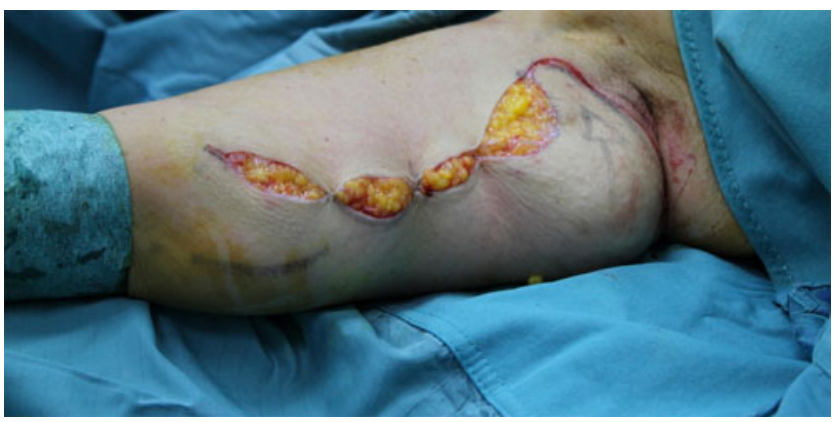

Fig. 12 Temporary suturing

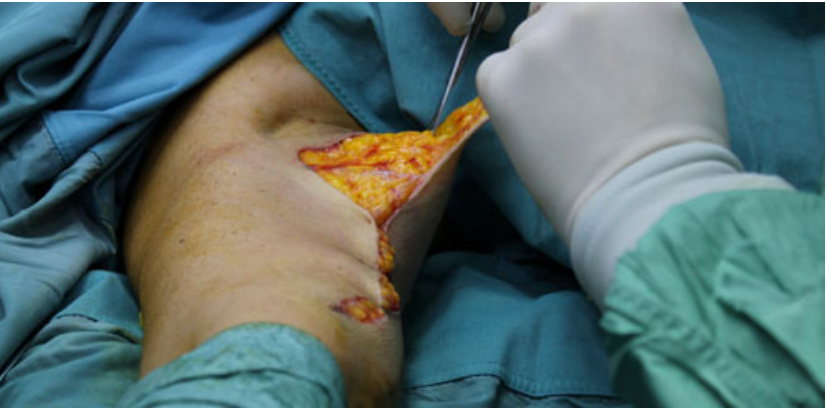

Fig. 13 Preparation of Flap B

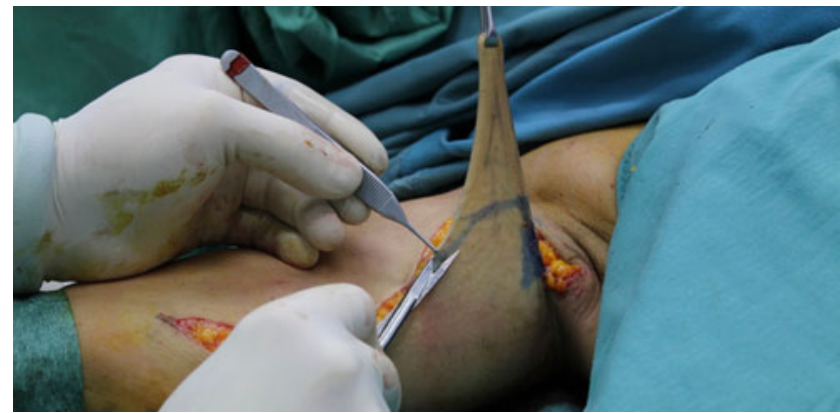

Fig. 14 Removal of excess skin from Flap B

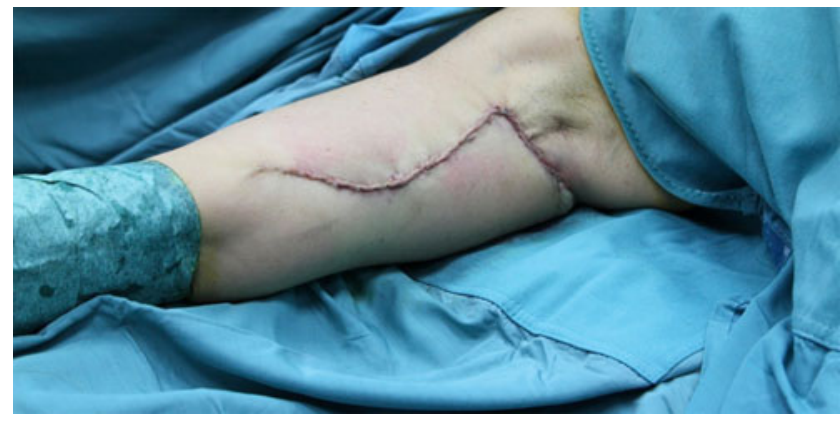

Fig. 15 Intradermic suture

Table 1 Patients demographics

No. of patients operated upon (2009-2013) 23

Average age of patients

55.4 years (36-77 years)

Female patients

20

Male patients

3

Associated liposuction

7 patients,

Average procedure time $1 \mathrm{~h}$ and $40 \mathrm{~min}$ 
ensuring traction of the skin of flap B and its surrounding area over three force vectors.

The penultimate step is therefore to apply the vertical and lateral traction to flap B to bring it closer to the armpit area. We can then remove the temporary suturing on flap A to bring that, too, closer to flap B. This ensures the correct tension during the healing process.

The final step is to close the incision by intradermic suturing (Fig. 15) using Monocryl 4.0. A medical compress is required for seven weeks, with manual lymphatic drain.

\section{Results}

Twenty-three patients were operated on between 2009 2013. The median age was 55.4 years; the youngest 36 and the oldest 77 . Twenty patients were female, with three male. Seven patients requested liposuction, which was performed prior to the brachial lifting procedure. None of the patients were undergoing bariatric surgery, and the typical procedure time was 100 minutes. Patients' demographics are summarized in Table 1 and representative cases are presented in Figs. 16, 17, 18, 19, 20, 21.

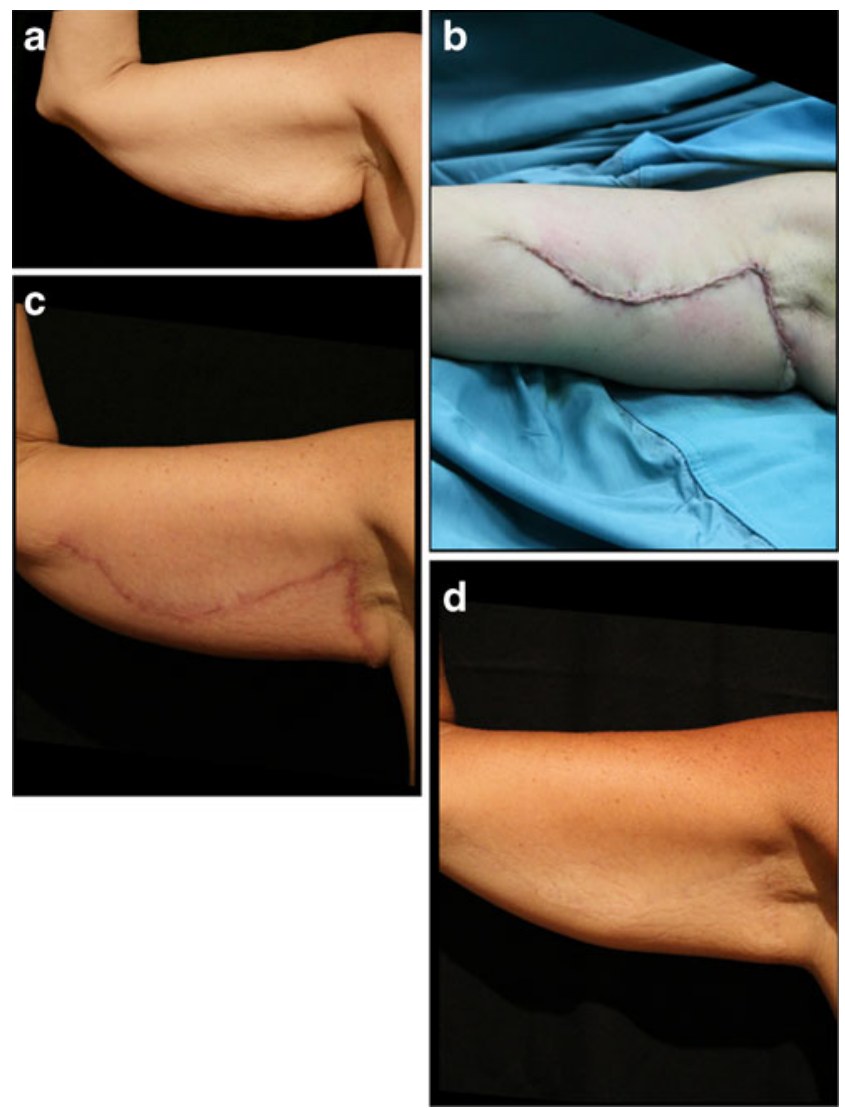

Fig. 16 a) Pre-operative condition of the patient's arm; b) immediate postoperative view; c) after 15 weeks and; d) after 80 weeks
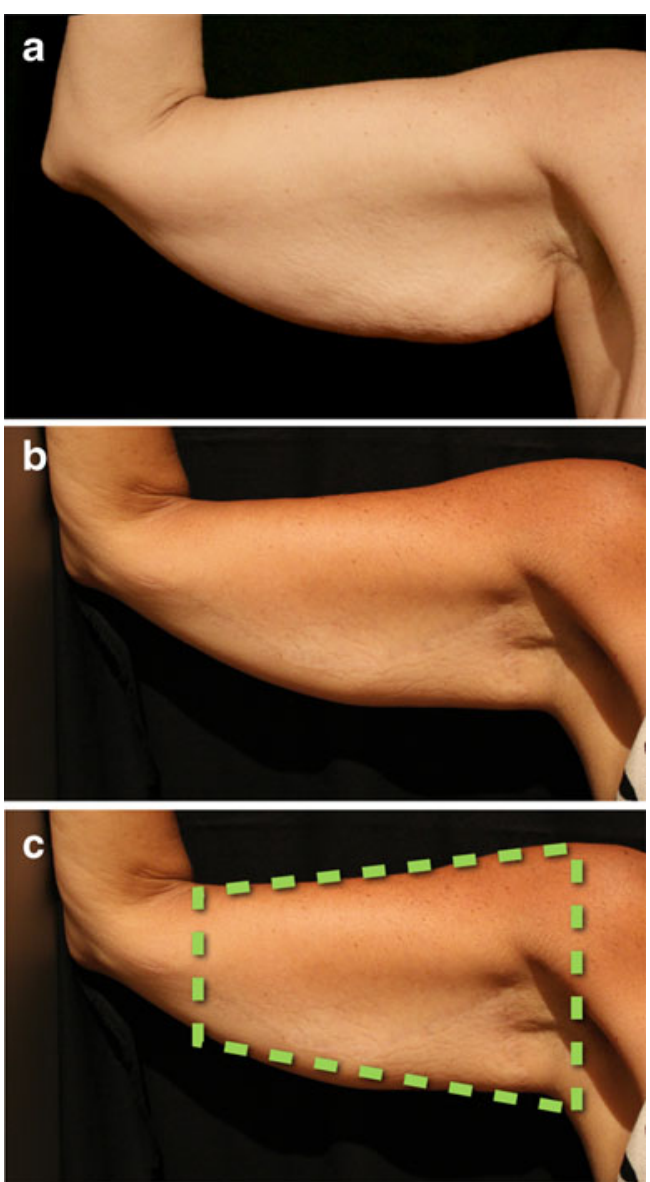

Fig. 17 The same patient depicted in Fig. 16 is shown again highlighting the before and after stages of the operation: a) preoperative view; b) post operative view at 80 weeks after surgery (the fading of the scar is clear); c) The use of the truncated cone (the 'frustum') to determine the excess skin to remove is illustrated here

\section{Post-op complications}

Table 2 summarises the post-op complications that arose. Of key importance is that no long-term or permanent complications arose. However, five patients reported temporary paraesthesia in their upper limbs, while two reported temporary loss of sensation, and two reported swelling of hands ( 9 temporary complications total). All these temporary complications resolved themselves naturally within three weeks, one week and 40 hours, respectively with no additional treatment required.

These issues are typically caused by the elastic compression applied during the first four weeks immediately after surgery. Seroma was reported only in one (male) patient. This was resolved within a week via pharmacological treatment. Eighteen patients had follow-up periods of at least 20 months. Of the 23 patients in total, only two required additional surgery for scar revision after the operation. Thirteen patients received corticoid therapy for the scarring. Finally, two 

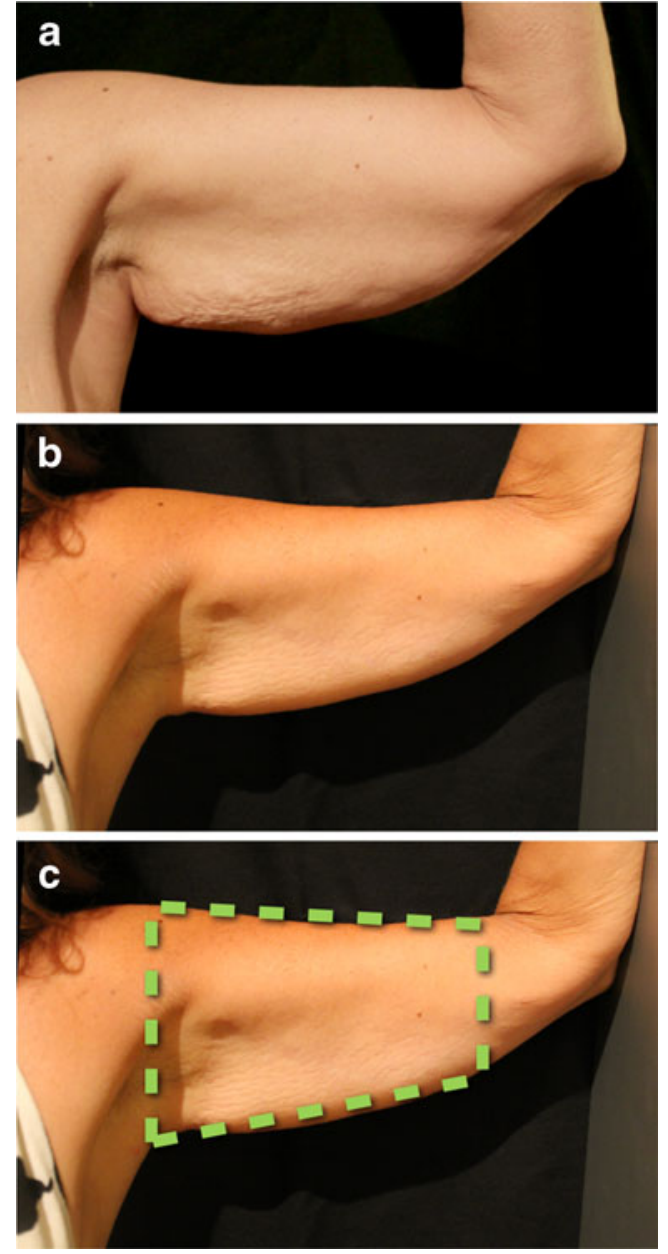

Fig. 18 Same patient, left arm: a) pre-operative view; b) post-operative view at 80 weeks; c) at 80 weeks with frustrum

patients had unusually visible scarring and underwent additional scar revision surgery.

Thirty days after surgery, a cream was applied locally (active ingredients: extractum cepae, heparin and allantoin), once every $24 \mathrm{~h}$, for at least 70 days.

\section{Discussion}

The balanced triple-vector approach avoids scar retraction and produces an aesthetic result in full compliance with the anthropometric research conducted within the art world.

The opposing traction of the 'A' and ' $\mathrm{B}$ ' dermo-cutaneous flaps results in three balanced vectors of force: the super-medial traction from flap A; the symmetrically opposing force from flap B; and, finally, the tension created between flap A and the axilla.

The triple force vector described is the keystone of this procedure as it greatly reduces scar retraction. As most brachial lifting procedures tend to apply only one force vector, they often result in scar retractions, and this is the most
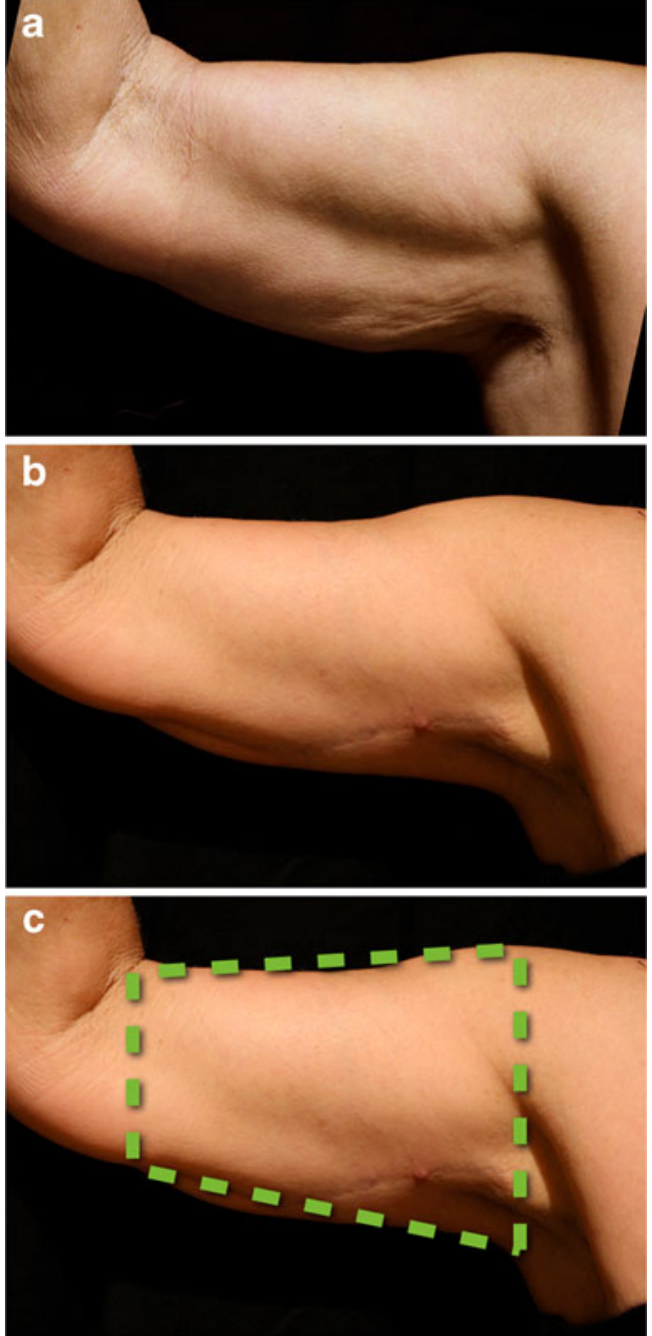

Fig. 19 a) Pre-operative view; b) post-operative view at 75 weeks; and c) view at 75 weeks with the truncated cone overlaid

common complication. In contrast, the balanced triple-vector tension created using the technique described here reduces such complications and results in a harmonious definition of the final arm contour. Furthermore, the superficial resection used in this technique - no damage to the subcutaneous tissue and lymphatic network occurs - results in a more predictable and reliable outcome.

The incision proposed differs from other approaches in not being strictly either sinusoidal or a straight line. Two curves are created, but these are asymmetric: that furthest from the axilla is typically three times the length of the other shorter curve. After the excess skin has been removed and traction has been applied to the flaps for the final time, the result is the creation of three balanced, and opposing, vectors of force. The surgical procedure is therefore performed in a very particular way, with the balancing of these vectors paramount. The procedure also involves the application of an anthropometric study of the arm (the conical frustum discussed earlier). 

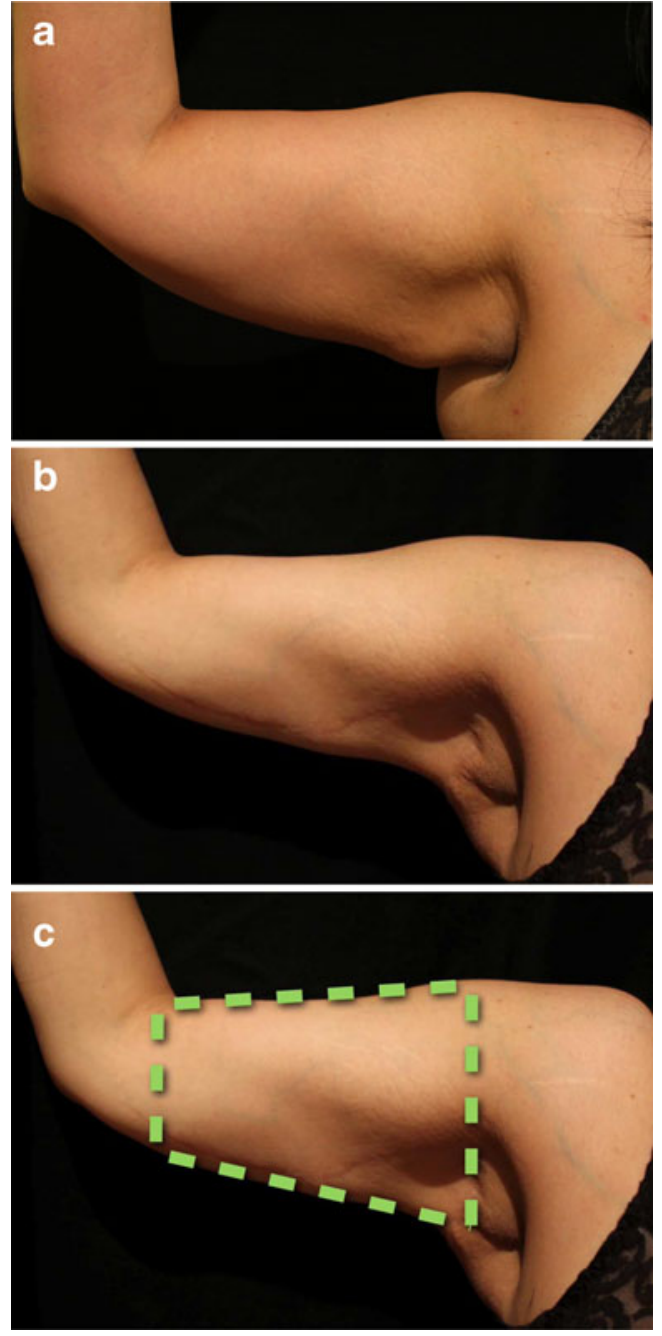

Fig. 20 a) Patient's right arm before the operation; b) view at 80 weeks after the operation; and c) view at 80 weeks with the truncated cone overlaid

The traction of the two flaps is performed in compliance with this study in order to produce the desired results.

My technique shares some aspects with the technique described by Pascal and Le Louarn in their 2005 paper, 'Brachioplasty' [3]. Similarly, Goddio [4] described a procedure in 1990 that takes an equally low-impact approach. I have retained the superficial incision to retain the integrity of the lymphatic and vascular structure of the arm. However, the incision planning and other details of my technique differ dramatically, particularly in the use of triple balanced force vectors. This 'light touch' philosophy contrasts strongly with alternative techniques that involve cutting down to the fascial system [5].

A study of the other literature in the field shows a number of schools of thought regarding the incision type. Many prefer the traditional straight line following the medial line between the biceps and triceps; others prefer
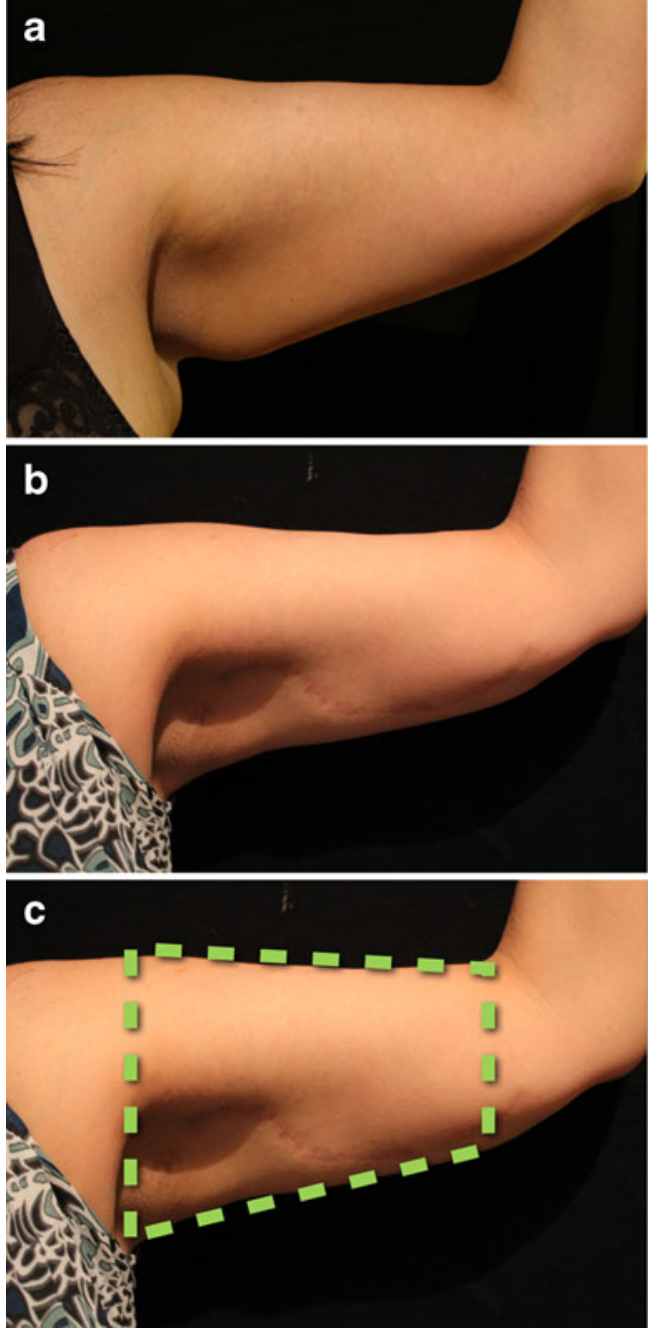

Fig. 21 Same patient, left arm: a) pre-operative view; b) postoperative view at 80 weeks; c) at 80 weeks with the truncated cone overlaid to illustrate how the surgery has produced an upper arm that aligns with the aesthetic anthropometric approach discussed earlier in the article

an incision directly along the arm's posterior brachial sulcus. In addition, there are those who advocate in favour of a sinusoidal rather than a straight-line incision $[4,5]$. Variations on the sinusoidal incision appear in the available

Table 2 Post-op complications

\begin{tabular}{ll}
\hline $\begin{array}{l}\text { Temporary paraesthesia } \\
\text { resolved naturally after } 3 \text { weeks }\end{array}$ & 5 patients, immediately post-op; \\
Temporary loss of sensation & 2 patients, immediately post-op; \\
resolved naturally after 1 week & \\
$\begin{array}{c}\text { Temporary swelling of hands } \\
\text { resolved naturally within } 40 \mathrm{~h}\end{array}$ & 2 patients, 8 days after operation; \\
$\begin{array}{l}\text { Seroma } \\
\text { Scar revision procedures that it } \\
\text { was required in two cases }\end{array}$ & 1 patient (male) \\
$\begin{array}{l}\text { Patients unsatisfied with final } \\
\text { scar quality }\end{array}$ & 1 patient \\
\hline
\end{tabular}


literature [6], but none appears to consider the need to balance multiple vectors of force, which I consider the key to my approach. Balancing these forces not only provides the most important contribution in improving the resulting arm contour from an anthropometric standpoint but also, crucially, greatly reduces the occurrence of scar hypertrophy and other post-op complications.

Zomerlei et al. [7] provide a telling survey of the problems caused by scarring. So much so that their survey concentrates primarily on the identification of scar types that appear aesthetically pleasing - the clear assumption here is that the scarring will never entirely fade away. In my hands, the scar created by using this technique seems to fade away entirely over time in the majority of cases, which is also related to the conservative excision of skin. Complications are very rare: since using this technique, I have had to perform only one scar review, giving a revision rate of $6.6 \%$ (compared with the $22.9 \%$ given by the study of Zomerlei et al. [7]) and a minor complication rate of $13.3 \%$ (compared with the $44.8 \%$ given, again, by Zomerlei et al. [7]).

The positioning of the incision is key to the procedure. Although the survey produced by Samra et al. [8] advises against using sinusoidal incisions due to the potential longterm scarring using traditional methods, the greatly reduced complications my balanced triple-vector method produces makes this type of incision much less problematic as the scarring is far more likely to heal entirely.

Whether the incision should be straight or curved has been proven to be a much more nuanced question than I think many of us realise. More research is needed that looks beyond the incision's rough shape and considers how that incision is used, including the force vectors applied, its depth and other characteristics.

\section{Conflict of interest None.}

Open Access This article is distributed under the terms of the Creative Commons Attribution License which permits any use, distribution, and reproduction in any medium, provided the original author(s) and the source are credited.

\section{References}

1. Rochet C (1887) Il Prototipo Umano Che Determina Le Leggi Naturali Delle Proporzioni In Ambedue I Sessi. Rome, Corso, 146: Modes \& Mendel, Librai-Editori, 32 pp (public domain)

2. Fantozzi F (2013) Applications of anthropometry in torsoplastic surgery. Eur J Plast Surg 36(8):519-526

3. Pascal JF, Le Louarn C (2005) Brachioplasty. Aesthetic Plast Surg 29(5):423-429

4. Goddio AS (1990) Brachioplasty. New technique. Ann Chir Plast Esthet 35(3):201-208

5. Lockwood T (1995) Brachioplasty with superficial fascial system suspension. Plast Reconstr Surg 96(4):912-920

6. Aboul Wafa AM (2013) S-shaped brachioplasty: an effective technique to correct excess skin and fat of the upper arm. Plast Reconstr Surg 131(4):661e-663e

7. Zomerlei TA, Neaman KC, Armstrong SD, Aitken ME, Cullen WT, Ford RD, Renucci JD, Vanderwoude DL (2013) Brachioplasty outcomes: a review of a multipractice cohort. Plast Reconstr Surg 131(4):883-889

8. Samra S, Samra F, Liu YJ, Sawh-Martinez R, Persing J (2013) Optimal placement of a brachioplasty scar: a survey evaluation. Ann Plast Surg 71:329-332 